\title{
TROMBOEMBOLIJOS RIZIKOS VEIKSNIŲ ANALIZĖ PACIENTAMS, SERGANTIEMS PRIEŠIRDŽIŲ VIRPĖJIMU, KOMPLIKUOTU IŠEMINIU INSULTU
}

\author{
Gabrielė Rudokaitè1, Augustė Ragelyte் ${ }^{1}$, Vytautas Zabiela ${ }^{2}$ \\ ${ }^{1}$ Lietuvos sveikatos moksly universiteto Medicinos fakultetas, \\ ${ }^{2}$ Lietuvos sveikatos mokslu universiteto ligoninès Kauno kliniku Kardiologijos klinika
}

Raktažodžiai: prieširdžių virpėjimas, išeminis insultas, tromboembolijų rizikos veiksniai.

\section{Santrauka}

Tyrimo tikslas: nustatyti prieširdžių virpèjimu (PV) sergančių pacientų, gydytų Lietuvos sveikatos mokslų universiteto ligoninès Kauno klinikų (LSMUL KK) Neurologijos skyriuje dèl išeminio insulto, tromboembolijos (TE) rizikos veiksnius bei būkles, turinčias įtakos TE komplikacijoms atsirasti. Tyrimo medžiaga ir metodai: i tyrimą įtraukti 110 atsitiktinai atrinktų pacientų, sergančių PV bei stacionarizuotų i LSMUL KK Neurologijos skyrių dèl išeminio insulto nuo 2016 gegužès iki 2018 vasario ménesio. Atlikta medicininių duomenų analizè, apskaičiuotas $\mathrm{CHA}_{2} \mathrm{DS}_{2}$-VASc balas, lygintas TE rizikos veiksniu paplitimas pagal lytị, PV tipą ir simptomiškumą. Statistinei analizei naudoti Mano Vitney (Mann-Whitney) U, Welch ANOVA, $\chi^{2}$ testai (SPSS 24.0). Rezultatai: iš 110 pacientų $47(42,73 \%)$ buvo vyrai ir $63(57,27 \%)$ moterys. Vidutinis išeminiu insultu sergančių pacientų $\mathrm{CHA}_{2} \mathrm{DS}_{2}$-VASc balas $-4,49 \pm 1,5$. 108 pacientams $(98,18 \%) \mathrm{CHA}_{2} \mathrm{DS}_{2}-$ VASc balas iki patiriant išemini insultą buvo $\geq 2$ balai. Reikšmingų skirtumų tarp TE rizikos veiksnių pasiskirstymo pagal lytị ir PV simptomiškumą nebuvo. Permanentiniu PV sergantieji reikšmingai dažniau buvo patyrę TE komplikacijas praeityje. Išvados: $98 \%$ pacientų, susirgusių insultu, TE rizika buvo didelè. Daugiau nei du trečdaliai ligonių nejautė ritmo sutrikimo simptomų. $15,5 \%$ pacientų prieširdžių virpejjimas pirmą kartą diagnozuotas stacionarizavimo dèl insulto metu.

\section{Ivadas}

Prieširdžių virpėjimas (PV) - tai dažniausiai nustatoma aritmija: bendras šios ligos paplitimas, įvairių autorių duo- menimis, siekia 1-2\% visos populiacijos, tačiau sergamumas PV kiekvienais metais dideja [1]. Tai siejama ne tik su pagerèjusia šios ligos diagnostika, bet ypač su ilgejjančia vidutine gyvenimo trukme, nes tikimybè susirgti PV dideja senstant ir kiekvieną dešimtmetị išauga net 2 kartus [1]. Senstant visuomenei PV tampa vis aktualesne problema ir todèl, kad jis yra siejamas su didesniu bendru mirtingumu, didesniu staigios širdinès mirties, išeminès širdies ligos, širdies nepakankamumo, lètinès inkstų ligos, periferinių arterijų ligos dažniu [2]. Be to, PV yra vienas pagrindinių išeminio insulto rizikos veiksnių. JAV atliktų epidemiologinių tyrimų duomenimis, PV sukelto išeminio insulto dažnis vis dideja ir siekia apie $22 \%$ [3]. Kitų tyrimų teigimu, net $9 \%$ vyrų ir $10 \%$ moteru, kuriems diagnozuotas $\mathrm{PV}$, susirgs išeminiu insultu, iš kurių beveik du trečdaliai per pirmuosius metus nuo diagnozès nustatymo [4]. Nemaža dalis PV atvejų yra asimptomiai [5], todèl didele problema išlieka nevèluojanti PV diagnostika - jis neretai diagnozuojamas tik pacientą ištikus išeminiam insultui ar kitai tromboembolinei (TE) komplikacijai [6]. Nustatyta, kad insultas gali būti pirmoji PV klinikinè išraiška 2-5 žmonèms iš 10000 gyventojų per metus [7].

Siekiant išvengti insulto ir kitų TE komplikacijų, svarbu ịvertinti šių komplikacijų riziką ir skirti reikiamą antitrombozinị gydymą. 2016 metais publikuotose Europos kardiologų draugijos PV gydymo gairèse išskiriama, kad didžiausią riziką susirgti išeminiu insultu sergant bet kurios formos PV lemia vyresnis pacientų amžius ( $\geq 65 \mathrm{~m}$.), stazinis širdies nepakankamumas ( $\breve{\mathrm{S} N})$, cukrinis diabetas $(\mathrm{CD})$, arterinè hipertenzija (AH), prieš tai buvę insultai, praeinantys smegenų išemijos priepuoliai ar TE komplikacijos bei kraujagysliu ligos (miokardo infarktas (MI), periferinių arterijų liga (PAL) ir moteriška lytis [8].TE rizika ịvertinama skaitine reikšme atsižvelgiant $i$ visus šiuos rizikos veiksnius apskaičiavus CHA2DS2-VASc balą. Ivvertinus TE rizikos laispnį, nusprendžiama, ar pacientui reikalingas antitrombozinis gydymas. 
Darbo tikslas: nustatyti PV sergančių pacientų, gydytų Lietuvos sveikatos mokslų universiteto ligoninès Kauno klinikų (LSMUL KK) Neurologijos skyriuje dèl išeminio insulto, TE rizikos veiksnius bei būkles, turinčias ịtakos TE komplikacijoms atsirasti.

\section{Tyrimo medžiaga ir metodai}

Tyrimo objektas - pacientai, sergantys PV bei stacionarizuoti i LSMUL KK Neurologijos skyrių dèl išeminio insulto. Tyrimo trukmè: 2016 gegužès mèn. - 2018 vasario mèn. I tyrimą įtraukta 110 atsitiktinai atrinktų pacientų, atlikta jų medicininių duomenų analizè. Ivvertintas pacientų amžius, lytis, PV tipas (paroksizminis, jei PV epizodas trunka iki 48 valandų; persistuojantis, jei PV epizodas tęsiasi daugiau nei 2 paras ir yra numatoma ritmo kontrolès taktika, permanentinis - trunkantis daugiau nei 1 metus arba priimtas sprendimas nebeatstatyti sinusinio ritmo), ritmas elektrokardiogramoje (EKG) stacionarizavimo dèl insulto metu, PV simptomatika, PV trukmè (ar jis diagnozuotas anksčiau, ar šio stacionarizavimo metu). Nustatyti tromboembolinių komplikacijų rizikos veiksniai: stazinis ŠN, arterinè hipertenzija (AH), buvę tromboemboliniai ịvykiai anamnezejje, cukrinis diabetas (CD), kraujagyslių patologija (miokardo infarktas (MI), periferinių arterijų liga (PAL)), apskaičiuotas CHA2DS2-VASc balas. Rizikos veiksnių bei kitų rodiklių pasiskirstymas analizuotas SPSS 25.0 programiniu paketu. Statistinei analizei naudoti Mano Vitney (Mann-Whitney)

1 lentelè. Insultą patyrusių pacientų pagrindinès demografinès ir PV charakteristikos

\begin{tabular}{|l|l|}
\hline Amžiaus vidurkis: & $74,75 \pm 9,93$ \\
moterų & $75,31 \pm 8,79$ \\
vyrų & $74 \pm 11,3$ \\
\hline $\begin{array}{l}\text { Amžiaus grupės: } \\
<65 \mathrm{~m} .\end{array}$ & $14(12,73 \%)$ \\
$65-74 \mathrm{~m}$. & $37(33,64 \%)$ \\
$75 \mathrm{~m}$. & $59(53,64 \%)$ \\
\hline $\begin{array}{l}\text { Pagrindinė liga: } \\
\text { IŚL }\end{array}$ & $39(35,45 \%)$ \\
AH & $69(2,73 \%)$ \\
Vožtuvų patologija & $2(1,82 \%)$ \\
\hline $\begin{array}{l}\text { PV tipas: } \\
\text { paroksizminis } \\
\text { persistuojantis } \\
\text { permanentinis }\end{array}$ & $35(31,82 \%)$ \\
\hline $\begin{array}{l}\text { Stacionarizavimo dèl insulto } \\
\text { metu pirmą kartą nustatytas } \\
\text { PV }\end{array}$ & $15(13,64 \%)$ \\
\hline $\begin{array}{l}\text { EKG stacionarizavimo metu: } \\
\text { PV } \\
\text { SR }\end{array}$ & $79(71,8 \%)$ \\
\hline
\end{tabular}

U testas, Welch ANOVA, Chi kvadrato kriterijus. Vidurkiai pateikiami su standartiniu nuokrypiu. Statistiškai patikimais laikyti tie atvejai, kai reikšmingumo lygmuo $p<0,05$. Šiam moksliniam tyrimui išduotas Bioetikos leidimas: Nr.BECMF-446.

\section{Rezultatai ir jų aptarimas}

Iš 110 atrinktų pacientų $47(42,73 \%)$ buvo vyrai ir 63 $(57,27 \%)$ moterys. Pacientų amžiaus intervalas nuo 48 iki 92 metų, o amžiaus vidurkis 74,75 $\pm 9,93$ metai. Kitos PV charakteristikos nurodytos 1-oje lentelèje.

Vidutinis išeminiu insultu sergančių pacientų $\mathrm{CHA}_{2} \mathrm{DS}_{2}-$ VASc balas $-4,49 \pm 1,5$. Net $98,18 \%$ ligonių turèjo didelę TE riziką $\left(\mathrm{CHA}_{2} \mathrm{DS}_{2}-\mathrm{VASc} \geq 2 \mathrm{~b}\right.$.), $1,82 \%$ atvejų rizika buvo vidutine $\left(\mathrm{CHA}_{2} \mathrm{DS}_{2}-\mathrm{VASc}=1 \mathrm{~b}\right.$.). Tarp insultą patyrusiuju mažos TE rizikos $\left(\mathrm{CHA}_{2} \mathrm{DS}_{2}-\mathrm{VASc}=0 \mathrm{~b}\right.$.) pacientų nebuvo (1 pav.). Analizuotas $\mathrm{CHA}_{2} \mathrm{DS}_{2}-\mathrm{VASc}$ balu pasiskirstymas pagal lyti (2 pav.). Tokie rezultatai parodo, kad absoliučiai daugumai pacientų, patyrusių insultą, buvo indikacijų skirti TE profilaktini gydymą antikoaguliantais: tai vyrai, kurių $\mathrm{CHA}_{2} \mathrm{DS}_{2}$-VASc balas $\geq 1$ balas ( $100 \%$ tirtų vyrų) ir moterys, kurių $\mathrm{CHA}_{2} \mathrm{DS}_{2}$-VASc balas $\geq 2$ balų $(98,41 \%$ tirtų moteru). Vienos pacientès TE rizika buvo vidutine $\left(\mathrm{CHA}_{2} \mathrm{DS}_{2}\right.$-VASc - 1b), kai TE profilaktika antikoaguliantais neindikuotina (1,2 pav.).

Ivertintas TE rizikos veiksnių (stazinio $\breve{S} \mathrm{~N}, \mathrm{AH}$, buvusių

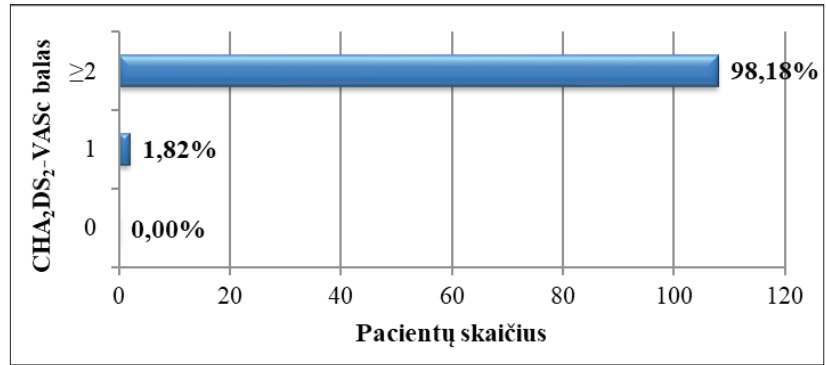

1 paveikslas. Pacientų TE rizika pagal $\mathrm{CHA}_{2} \mathrm{DS}_{2}-\mathrm{VASc}$ balą.

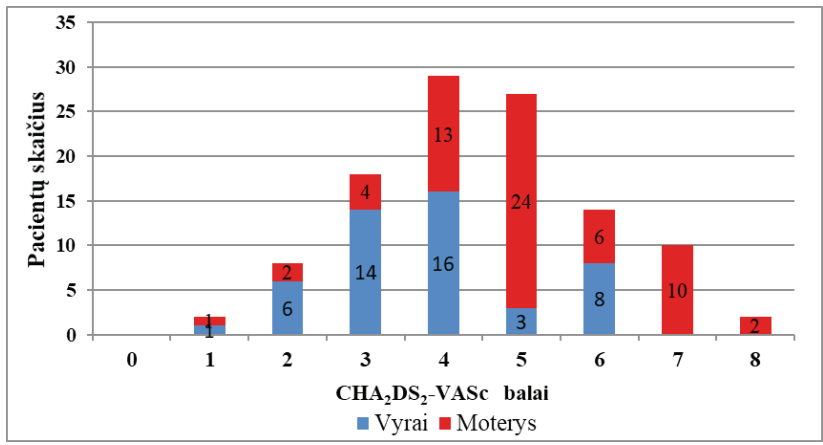

2 paveikslas. $\mathrm{CHA}_{2} \mathrm{DS}_{2}$-VASc balų pasiskirstymas pagal pacientų lyti. 
tromboembolinių ịvykių anamnezėje, kraujagyslių patologijos, CD) paplitimas pagal lyti, statistiškai reikšmingu skirtumų tarp ịvairių veiksnių pasiskirstymo nustatyta nebuvo (2 lentelè).

Iš analizuotų pacientų net $69,09 \%(n=76)$ nejuto $\mathrm{PV}$ simptomų. Nustatyta, kad tiriamosios moterys statistiškai reikšmingai dažniau patiria PV simptomus nei vyrai: 19,1\% vyrų ( $\mathrm{n}=9)$ yra patyrę PV simptomus, o 80,9\% $(\mathrm{n}=38)$ - nepatyrę, lyginant su $39,7 \% \quad(n=25)$ simptominių ir $60,3 \%$ $(\mathrm{n}=38)$ asimptominių moteru $(\mathrm{p}<0,05)$. (3 lentelè)

Nagrinejjant simptominių ir asimptominių pacientų grupes paaiškèjo, kad TE rizika reikšmingai nesiskyrè, tačiau vertinant stacionarizavimo dèl insulto EKG pacientams,

2 lentelè. TE rizikos veiksniai ir balas pagal lytị.

\begin{tabular}{|l|l|l|l|}
\hline \multirow{2}{*}{} & \multicolumn{2}{|c|}{ Paciento lytis } & \multirow{2}{*}{ p } \\
\cline { 2 - 3 } & \multicolumn{1}{|c|}{ Moterys } & \multicolumn{1}{c|}{ Vyrai } & \\
\hline Stazinis ŠN & $29(50,88 \%)$ & $28(49,12 \%)$ & 0,16 \\
\hline AH & $43(41,35 \%)$ & $61(58,65 \%)$ & 0,223 \\
\hline $\begin{array}{l}\text { Insultas, TE anam- } \\
\text { nezejje }\end{array}$ & $18(66,67 \%)$ & $9(33,33 \%)$ & 0,256 \\
\hline MI, PAL & $6(54,54 \%)$ & $5(45,45 \%)$ & 0,847 \\
\hline CD & $7(58,33 \%)$ & $5(41,67 \%)$ & 0,937 \\
\hline $\begin{array}{l}\mathrm{CHA}_{2} \mathrm{DS}_{2} \text {-VA Sc } \\
\text { balo vidurkis }\end{array}$ & $3,79 \pm 1,3$ & $5,03 \pm 1,44$ & - \\
\hline
\end{tabular}

3 lentelè. Pacientų charakteristikos pagal PV simptomiškumą. *-kai $p<0,05$.

\begin{tabular}{|c|c|c|c|}
\hline & \multicolumn{2}{|c|}{ PV simptomiškumas } & \multirow[t]{2}{*}{$\mathbf{p}$} \\
\hline & Simptominis & $\begin{array}{l}\text { Asimptomi- } \\
\text { nis }\end{array}$ & \\
\hline $\begin{array}{l}\text { Pagrindinė liga: } \\
\text { ISSL } \\
\text { AH } \\
\text { Vožtuvinis PV }\end{array}$ & $\begin{array}{c}10(25,64 \%) \\
23(33,33 \%) \\
1(50 \%) \\
\end{array}$ & $\begin{array}{c}29(74,36 \%) \\
46(66,67 \%) \\
1(50 \%)\end{array}$ & 0,595 \\
\hline $\begin{array}{l}\text { Lytis: } \\
\text { moteris } \\
\text { vyras } \\
\end{array}$ & $\begin{array}{c}25(39,68 \%)^{*} \\
9(19,15 \%) \\
\end{array}$ & $\begin{array}{l}38(60,32 \%) \\
38(80,85 \%)\end{array}$ & 0,021 \\
\hline $\begin{array}{l}\text { Stacionarizavimo } \\
\text { EKG: } \\
\text { SR } \\
\text { PV }\end{array}$ & $\begin{array}{l}19(61,29 \%) \\
15(18,99 \%) \\
\end{array}$ & $\begin{array}{c}12(38,71 \%) \\
64(81,01 \%)^{*}\end{array}$ & $<0,0001$ \\
\hline $\begin{array}{l}\text { PV tipas: } \\
\text { Parokzisminis } \\
\text { Persistuojantis } \\
\text { Permanentinis }\end{array}$ & $\begin{array}{c}23(67,71 \%) \\
8(53,33 \%) \\
3(5 \%)\end{array}$ & $\begin{array}{c}12(34,29 \%) \\
7(46,67 \%) \\
57(95 \%)^{*}\end{array}$ & $<0,001$ \\
\hline Stazinis ŠN & $15(26,32 \%)$ & $42(73,68 \%)$ & 0,28 \\
\hline $\begin{array}{l}\text { Insultas ar kita TE } \\
\text { anamnezèje }\end{array}$ & $6(22,22 \%)$ & $21(77,78 \%)$ & 0,261 \\
\hline MI, PAL & $4(36,36 \%)$ & $7(63,64 \%)$ & 0,68 \\
\hline $\mathrm{CD}$ & $2(16,67 \%)$ & $10(83,33 \%)$ & 0,258 \\
\hline $\begin{array}{l}\mathrm{CHA}_{2} \mathrm{DS}_{2}-\mathrm{VASc} \\
\text { balo vidurkis }\end{array}$ & $4,41 \pm 1,5$ & $4,51 \pm 1,2$ & 0,745 \\
\hline
\end{tabular}

4 lentelè. TE rizika ir veiksnių pasiskirstymas pagal PV tipą. $*$ - $p<0,05$.

\begin{tabular}{|l|c|c|c|c|}
\hline & \multicolumn{3}{|c|}{ PV tipas } & p \\
\cline { 2 - 5 } & $\begin{array}{c}\text { Paroksiz- } \\
\text { minis }\end{array}$ & $\begin{array}{c}\text { Persistuo- } \\
\text { jantis }\end{array}$ & $\begin{array}{c}\text { Permanen- } \\
\text { tinis }\end{array}$ & \\
\hline $\begin{array}{l}\text { Pagrindinė liga: } \\
\text { IŠL } \\
\text { AH } \\
\text { vožtuvu patologija }\end{array}$ & $\begin{array}{c}7(17,95 \%) \\
28(40,58 \%) \\
7(0 \%)\end{array}$ & $\begin{array}{c}7(17,95 \%) \\
1(50 \%)\end{array}$ & $\begin{array}{c}25(64,1 \%) \\
34(49,27 \%) \\
1(50 \%)\end{array}$ & 0,067 \\
\hline Stazinis ŠN & $20(37,74 \%)$ & $5(9,43 \%)$ & $28(52,83 \%)$ & 0,268 \\
\hline $\begin{array}{l}\text { Insultas ar kitos } \\
\text { TE komplikacijos } \\
\text { anamnezėje }\end{array}$ & $6(22,22 \%)$ & $1(3,7 \%)$ & $\begin{array}{c}20 \\
(74,07 \%) *\end{array}$ & 0,047 \\
\hline MI, PAL & $3(27,27 \%)$ & $2(18,18 \%)$ & $6(54,55 \%)$ & 0,876 \\
\hline CD & $3(25 \%)$ & $0(0 \%)$ & $9(75 \%)$ & 0,219 \\
\hline $\begin{array}{l}\text { CHA D } \\
\text { balo vidurkis }\end{array}$ & $4,37 \pm 1,57$ & $3,6 \pm 1,33 *$ & $4,78 \pm 1,42$ & 0,019 \\
\hline
\end{tabular}

nejaučiantiems ritmo sutrikimo, reikšmingai dažniau nustatytas PV $(\mathrm{p}<0,05)$. Pacientai, sergantys permanentiniu PV, statistiškai reikšmingai dažniau nejautè ritmo sutrikimo simptomų $(\mathrm{p}<0,05)$.

Analizuojant TE rizikos veiksnius pagal PV tipą (4 lentelè) pastebèta, jog praeityje buvę tromboemboliniai ịvykiai dažnesni permanentinio PV atveju (33,3\%), retesni esant paroksizminiam PV (17,1\%), o rečiausi, kai PV persistuojantis $(6,7 \%)(p<0,05)$. Tačiau persistuojančio PV atveju statistiškai reikšmingai mažesnis bendras TE rizikos balų (CHA2DS2-VASc) vidurkis $(3,6)$ lyginant su permanentiniu $(4,78)$ bei paroksizminiu $(4,37)$ PV $(p<0,05)$.

Iš 110 pacientų $93(84,5 \%)$ PV buvo diagnozuotas anksčiau, $17(15,5 \%)$ - tik stacionarizavimo dèl insulto metu. Pirmą kartą PV buvo diagnozuotas 6 vyrams $(12,8 \%)$ ir 11 $(17,5 \%)$ moterų. Nagrinètose amžiaus grupèse šie rodikliai pasiskirste taip: pirmą kartą tik ištikus išeminiam insultui PV buvo diagnozuotas 3 (21,4\%) pacientams iki 65 m., 5 $(13,5 \%) 65-75 \mathrm{~m}$. pacientams ir $9(15,3 \%)$ pacientams per 75 $\mathrm{m}$. Lyginant anksčiau diagnozuotus ir tik šio stacionarizavimo metu nustatytus $\mathrm{PV}$ atvejus, jokių reikšmingų rizikos veiksnių pasiskirstymo skirtumų nenustatyta. TE rizikos balas reikšmingai nesiskyrè: pirmą kartą diagnozuoto PV atveju CHA2DS2-VASc balo vidurkis 4,11 $\pm 1,2$, o anksčiau dokumentuoto PV - 4,56 $\pm 1,46$.

\section{Išvados}

1. Absoliuti dauguma pacientų, sergančių PV ir stacionarizuotų dèl insulto, turejjo didelę tromboembolinių komplikacijų riziką.

2. $69,09 \%$ pacientų nejuto PV simptomų.

3. Moterys dažniau patyrẻ PV simptomus nei vyrai. 
4. Praeityje buvę tromboemboliniai ịvykiai dažnesni permanentinio PV atveju.

5. $15,5 \%$ pacientų PV pirmą kartą diagnozuotas tik ištikus išeminiam insultui.

\section{Literatūra}

1. Andrade J, Khairy P, Dobrev D, Nattel S. The clinical profile and pathophysiology of atrial fibrillation: relationships among clinical features, epidemiology, and mechanisms. Circ Res 2014;114(9):1453-1468.

https://doi.org/10.1161/CIRCRESAHA.114.303211

2. Odutayo A, Wong CX, Hsiao AJ, Hopewell S, Altman DG, Emdin CA. Atrial fibrillation and risks of cardiovascular disease, renal disease, and death: systematic review and metaanalysis. BMJ 2016;354:i4482. http://www.ncbi.nlm.nih.gov/ pubmed/27599725. Accessed March 2, 2018.

https://doi.org/10.1136/bmj.i4482

3. Otite FO, Khandelwal P, Chaturvedi S, Romano JG, Sacco RL, Malik AM. Increasing atrial fibrillation prevalence in acute ischemic stroke and TIA. Neurology 2016; 87(19):2034-2042. https://doi.org/10.1212/WNL.0000000000003321

4. Son MK, Lim N-K, Kim HW, Park H-Y. Risk of ischemic stroke after atrial fibrillation diagnosis: a national sample cohort. Bishopric NH, ed. PLoS One 2017;12(6):e0179687.

https://doi.org/10.1371/journal.pone.0179687

5. Orlov M V., Ghalijk, Araghi-Niknam M. et al. Asymptomatic atrial fibrillation in pacemaker recipients: incidence, progression, and determinants based on the atrial high rate trial. Pacing Clin Electrophysiol 2007; 30(3):404-411.

https://doi.org/10.1111/j.1540-8159.2007.00682.x

6. Healey JS, Connolly SJ, Gold MR. et al. Subclinical atrial fibrillation and the risk of stroke. N Engl J Med. 2012;366(2):120129.

https://doi.org/10.1056/NEJMoa1105575

7. Lubitz SA, Yin X, McManus DD. et al. Stroke as the initial manifestation of atrial fibrillation. Stroke. 2017; 48(2):490-492. https://doi.org/10.1161/STROKEAHA.116.015071
8. Lip GYH. Recommendations for thromboprophylaxis in the 2012 focused update of the ESC guidelines on atrial fibrillation: a commentary. J Thromb Haemost 2013;11(4):615-626. https://doi.org/10.1111/jth.12140

\section{ANALYSIS OF THROMBOEMBOLIC RISK FACTORS IN ISCHEMIC STROKE PATIENTS WITH ATRIAL FIBRILLATION}

\section{G.Rudokaité, A.Ragelytė, V.Zabiela}

Key words: atrial fibrillation, ischemic stroke, thromboembolic risk factors.

Summary

Objective: to evaluate thromboembolic risk factors in stroke patients with atrial fibrillation $(\mathrm{AF})$, who were treated at Lithuania Health Sciences Hospital Kaunas Clinics (LHSH KC) Neurology department. Methods: 110 randomly selected stroke patients with $\mathrm{AF}$, who were treated at LHSH KC Neurology department from 2016 May to 2018 February, were included to the study. Medical records were analysed, $\mathrm{CHA}_{2} \mathrm{DS}_{2}$-VASc score was calculated for each subject. Difference of thromboembolic risk factors distribution according to patients' sex, AF type and symptoms was evaluated. Data analysis was performed using Mann-Whitney U, Welch's ANOVA, $\chi^{2}$ test (SPSS 24.0). Results: among the study patients, $47(42,73 \%)$ were males and $63(57,27 \%)$ were females. Average $\mathrm{CHA}_{2} \mathrm{DS}_{2}$-VASc score was $4,49 \pm 1,5.108(98,18 \%)$ patients had $\mathrm{CHA}_{2} \mathrm{DS}_{2}$-VASc score greater than or equal to 2 . There was no significant difference in the distribution of risk factors between both sexes and symtomic vs. asymptomic AF groups. Prior stroke and other thromboembolic complications were observed statistically significant more often in permanent AF group $(\mathrm{p}<0.05)$. Conclusions: $98 \%$ of stroke patient with AF had high risk of thromboembolism. Two thirds of patients did not have any symptoms of arrhythmia. $15,5 \%$ of patients were diagnosed with $\mathrm{AF}$ when ischemic stroke occurred.

Correspondence to: g.rudokaite@gmail.com

Gauta 2018-03-21 